\title{
The Use of Computer Programs and Applications by Undergraduates and its Relations to their Motivation toward E-learning and Academic Performance
}

\author{
Nahil Mohammad Al-Jaberi
}

Faculty of Arts, University of Petra, Amman, Jordan

Corresponding author: Nahil M Aljaberi, E-mail: naljaberi@uop.edu.jo

\section{ARTICLE INFO}

Article history

Received: 26, 2018

Accepted: October 24, 2018

Published: October 31, 2018

Volume: 6 Issue: 4

Conflicts of interest: None

Funding: None

\begin{abstract}
This study aims to investigate the level of use of computer software and applications, and how it affects motivation toward e-learning as well as academic performance and achievement. The researcher selected a study sample of 500 male and female undergraduates at Petra University. Furthermore, two scales were implemented for the purpose of this research; the first investigated the level of use and integration of programs and applications, and the other investigated how motivated learners were toward e-learning with the use of such applications and programs. The study identified applications most commonly used by undergraduates, with social media networks, E-mails, and smart phones in the lead. Moreover, findings indicated a positive correlation between the level of applications and computer programs use and motivation toward e-learning. However, no correlation was found between the level of implementation and motivation toward e-learning; likewise, academic achievement and faculty were not effective in differentiating motivation levels. However, the variables of academic level and sex were statistically significant in favor of male and older students in their motivation toward e-learning.
\end{abstract}

Key words: Computer Programs, Motivation, Computer Application, e-Learning

\section{INTRODUCTION}

In the last decade digitally-dominated and information-packed era, known as Digital or Information Age, has made significant changes in our life-style. The changes caused by technological improvement not only have affected our everyday life, but also affected education, in changing its aims, fields, and teaching methods. This change caused an increase in various new jargons and in modern teaching methods, such as e-learning, online learning, distance learning, m-learning (mobile learning) and a variety of other methods which seek to integrate technology into the learning and teaching process. In the Digital and Information Age, acquiring knowledge is no longer seen as the main objective of the learning process. This era requires individuals capable of continuous self-learning, which cannot be achieved unless they come to possess a sufficient amount of internal motivation imposed by the e-learning environment which encourages learning and commitment to continuity (Shroff et al., 2007).

Motivation is a main requirement for the success of any educational process, for it is the driving force that pushes a learner toward producing better outcomes. Research shows that motivation is one of the most significant factors in the process of learning (Harandi, 2015; Miljković et al., 2016; Wu \& Hwang, 2010). The more the students are motivated to learn, the better they perform. For this reason, motivation toward learning comprised a large part of this research, just as it has been the target of numerous studies in the $21^{\text {st }}$ century. Ongoing research as such in the past couple of decades has produced motivation theories independent in personality-related concepts and numerous other dimensions. This outcome was the result of acknowledging motivation's importance in interpreting, shaping, and altering human behaviour, as well as how strongly it is related to classroom teaching and learning. Designing an e-learning environment fundamentally differs from the process of designing traditional learning environments. One of the most crucial factors that ought to be taken into consideration when setting an e-learning environment up is students' motivation toward learning. For instance, Keller (2008) asserts that the majority of learning environments today integrate technology to assist learning and teaching. A number of these could be described as self-guided or self-driven by the learner, whereas others are guided by the teacher.

Furthermore, Keller (2008) argues that integrating assistive technology in the educational process is increasing, as many are relying on technology, online learning, and smart phones (m-learning). Hartnett, St George, and Dron (2011a,b) and Alrashdan and Janini (2006) indicate that motivation is the process which boosts a student's activeness and desire to learn, as it affects what, how, and when we learn, how we choose and what we want to learn. This is 
because students' motivation is connected to their interests and needs. Additionally, Brophy (2010) argues that contemporary viewpoints indicate a correlation between motivation and learners' thinking skills and their cognitive processes, thoughts, beliefs, goals, aspirations, circumstances, and the interactive relationship between them and their environment. Miqdad (2010) further asserts that motivation in e-learning differs from that of traditional teaching; for instance, motivation is much higher in e-learning since it engages one half of the educational process which does not apply to traditional learning. Thus, strategies aiming to increase motivation in regular teaching are not necessarily effective in their pursuit, and differ greatly from those in e-learning. Consequently, we have to think of alternative strategies that are more suitable for e-learning.

Gabrielle (2003) points out that transmitting from teacher-centred learning to student-centred learning prompts learners to become internally motivated toward the process. Miljković et al. (2016) believe that e-learning is a very complicated process where numerous factors and sub-processes overlap e-learning and long distance learning. For this reason, we could argue that motivating students and setting up a learning process are two of the most challenging achievements in meeting learners' needs.

Law et al. (2010) argue that integrating computer programs and applications into the classroom also fuel learners' motivation toward learning. According to Sun et al. (2008), helping students build self-confidence through working with computers can make e-learning more enjoyable. This clears the way for effective learning to occur, where the learning experience becomes deeper, more long-lasting, and easier to grasp for learners who are experiencing active learning (whether individually or in a group), as proposed by the theory of constructivism (Al-Jaberi, 2011; Shenker et al., 1996). Topal (2016) reported that there are high satisfaction and motivation levels among students who direct their learning internally, and that such learners are highly capable of controlling and managing their learning process. Furthermore, Marten et al. (2004) indicate that students with high self-motivation perform significantly better than their peers with low self-motivation levels. Research findings stress the importance of increasing the amount of resources put into online courses, giving more significance to interaction, and facilitating the use of various multimedia tools to ensure higher student satisfaction levels (Kim \& Malhotra, 2005; Ryan \& Deci, 2000; Topal, 2016). On the contrary, Keller (2008) believes that boosting learners' motivation toward learning requires fuelling their curiosity and feeding their internal conviction of being capable of succeeding, where positive reinforcement should be based on each learner's individual learning experience. Likewise, Mullen and Tallent-Runnels (2006) argue that understanding a learner's motivation is essential for judging the effectiveness of the teaching process. Furthermore, they emphasize the importance of being aware of teaching strategies in e-learning environments, which are seen as the most motivating learning environments of all. In addition, Mahdizadeh et al. (2008) and Giesbers et al. (2013) state that the actual use of computer programs and effective contributions made toward the learning process depend on how motivated students are toward learning.

\section{Related past studies}

A number of studies have found that learners who possess motivation toward learning are better at making logical connections, listening, making use of a deep approach toward learning, enhancing performance, heightening their sense of creativity, diligence, and taking part in instructional activities.

Studies examined the impact of the use of computer programs and application on students' motivation towards e-learning: Anqithan (2009) is study tackled e-learning and motivation toward e-learning. He has found that using power point program caused a positive increase in motivation. Another study by Gabrielle (2003) aimed to reveal the positive effects on motivation and performance in undergraduates through delivering enriching e-learning courses. The findings indicated statistically significant differences between the experimental and control groups regarding students' motivation toward learning and academic performance and their inclination toward self-learning.

Other studies focused on the relationship between the design of e-learning environments and motivation towards e-learning. Miqdad (2010) tackles motivation levels in learners engaged in e-learning. The findings indicate that effective strategies must be arranged for e-learning environments (especially in regards to attention, suitability, confidence, and satisfaction). Rovai et al. (2007) aimed to compare motivation levels in two samples, one which received traditional teaching, and another which sat for an e-learning course. The findings indicate that students who had undergone the e-learning course had higher motivation levels; further, the results show that post-graduates had the highest level of motivation as compared to graduates.

Yet another group of studies examined the factors that affect the motivation of learners towards e-learning and the tendency of students towards e-learning and satisfaction. A study by Kim and Frick (2011) explored the factors which contribute in most of the students' motivation in online teaching, the level of motivation in learners, how it differs in accordance with subject areas, and which factors are related to changing their motivation levels. Hartnett et al. (2011a, b) conducted a study in New Zealand to investigate motivation in pre-service teachers who teach two different subjects in online learning environments. Findings concluded that motivation toward learning is a complex and interrelated process, and that learners in the online learning environment were not internally motivated as previously argued by other studies in the field. When designing a learning environment, it is important to take the factors of the learning context into consideration, as well as setting goals and allowing for discussion, reflection, and a variety of choices for learners to find motivation for continuous learning.

A study by Kim \& Frick (2011), found that motivation and satisfaction in learners engaged in online learning increases when students find that the subject at hand is related to practical life, the technology used is user-friendly, the will 
to engage in continuous self-learning is strong, and when they constantly believe that they have the right to self-learning, and when they receive continuous efforts and support before and during the course taught. A study by Selim (2007) examined the factors affecting the acceptance of e-learning. The study concluded that there is a clear acceptance of learning through e-learning environments and the internet. The study also stressed the importance of motivation as an important factor in the acceptance of e-learning. A study by Law, Lee and Yu, (2010) confirmed that the motivation towards e-learning is the most important factors affecting the success of the learning process. The study also developed a model in which all factors affecting the motivation towards e-learning were investigated. A Study by Liaw, and Huang, (2011), examined the attitudes of students towards e-learning. The study showed that the attitudes of male students are more positive than female students. Experience and continuous interaction with computer programs and computer technology increase self-efficacy and confidence in e-learning.

The relation between using e-learning and the students' achievement were also conducted. Nehme (2010) conducted a study on controlling learning environments through programs such as WebCT and B.b. (and others) on a sample of undergraduate. The findings further indicate that the better student-teacher interactions are, the better learners' motivation and academic performance become, and the more committed and less stressed they are. Another study by Gabrielle (2003) aimed to reveal the positive effects on motivation and performance in undergraduates through delivering enriching e-learning courses. The findings indicated statistically significant differences between the experimental and control groups regarding students' motivation toward learning and academic performance and their inclination toward self-learning.

\section{Objective and Research Questions}

This study aims to investigate the connections between motivation toward e-learning and to which level undergraduate learners use technological e-learning. It also investigates the relationship between motivation toward e-learning and the academic achievements of undergraduate students.

The study aims to answer the following:

1. Is there a correlation between the level of use computer programs and applications, and motivation toward e-learning and academic achievement?

2. Are there any statistically significant differences in the level of motivation toward e-learning on the variable of sex, academic level and faculty at which undergraduates are enrolled?

\section{Significance of study}

The significance of this study lies in identifying the most commonly used computer programs and applications among undergraduates, as well as highlighting the correlation between the level to which these applications and programs are used and how motivated students are toward e-learning. In addition, the study is important in that it seeks to investigate the effect of using and integrating computer programs and applications on the academic achievement levels of undergraduates, and whether the variables of sex, academic faculty, and academic level have any significant impact on motivation toward e-learning. The findings should serve as recommendations and guidelines for decision-makers when designing and setting up educational programs and professional development plans for higher education.

\section{METHODS}

The quantitative approach (descriptive and correlative) was used in this study in order to reveal:

1. The level of university students' use of computer applications and software

2. The level of students' motivation of towards e-learning.

3. The correlation between the level of use of software and computer applications and student motivation towards e - learning.

4. The impact of gender, college and academic level on the motivation of students towards e-learning.

\section{Study Sample and Community}

The researcher selected a random sample of 500 male and female undergraduate students registered at the University of Petra, a private university in Amman with a student population of 5,500 undergraduates enrolled in the first semester. The selected samples included students who have taken a number of courses which made use of computer programs, including B.B. (Black Board) and Moodle, or have integrated other computer-based programs in other faculties and majors at the university. The sample consisted of 233 male students (46.6\%) and 267 female students (53.4\%). In terms of faculty, 114 students were enrolled in the Faculty of Arts and Sciences (22.8\%), 157 were enrolled in the Faculty of Administrative Sciences (31.4\%), 61 in the Faculty of Pharmacy $(12.2 \%), 44$ in the Faculty of Information Technology $(8.8 \%)$, and 124 in the Faculty of Architecture and Interior Design (24.8\%). The sample also included 130 freshmen (26\%), 101 sophomores (20.2\%), 125 juniors (25\%), 111 seniors $(22.2 \%)$, and 33 super seniors $(6.6 \%)$. Of these, 92 students received traditional learning (18.4\%), while 347 received a mix of traditional learning and e-learning (69.4\%), and 61 received e-learning only (12.2\%). Of the sample, 122 students had a GPA below 2.00 (out of 4) (24.4\%), while 202 had a GPA between 2.00 and $2.33(40.4 \%)$, and 124 students had a GPA between 2.34 and 3.33 (24.8\%), and finally 55 students had a high GPA between 3.34 and 4 (10.4\%). Table (1) illustrates these numbers divided into the faculty and major variables.

\section{Study Variables}

In this study, e-learning includes any form of learning that integrates computer technologies, whether online or using LANs, mobile, learning management programs such as B.B or Moodle, social media networks, search engines, and educational applications. 
Table 1. Student motivation toward e-learning

\begin{tabular}{lccc}
\hline Motivation level & No. & Sum & Mean \\
\hline High & 69 & 5687 & 82.4 \\
Moderate & 157 & 9129 & 58.15 \\
Low & 274 & 6297 & 22.98 \\
\hline
\end{tabular}

\section{Motivation toward e-learning}

Motivation is a concept that is difficult to measure, Ghergulescu and Muntean $(2010 \mathrm{a}, \mathrm{b})$ assert that motivation is the incentive (psychological feature) or energy that drives a learner to fulfill an intellectual objective, engage in the learning process, and maintain it. Moreover, Al-Isawi (2011) asserts that motivation (from a behavioral perspective) is the internal or external state of the learner, which drives his or her behavior and performance toward the goal or objective while maintaining continuity. Cognitively speaking, it is an internal status which moves the ideas, knowledge, cognitive awareness, and attention of the learner. As from the perspective of humanities, motivation is an inner self-driven state which moves a learner toward investing his or her maximum effort in any learning context with the aim of fulfilling his or her desires and reaching a state of self-actualization.

Procedural definition for the "Motivation toward e-learning":

It is the sum of students' acceptance or rejection responses towards learning through technological applications and computer software, which is considered an e-learning model, and is measured by the total scores obtained by the students who answer the score sheets prepared by the researcher for this purpose.

\section{Instruments (Data Collection Tools)}

This study utilized the following tools for data collection:

Level of computer program and application use in the learning process scale:

This scale was developed by the researcher with the aim of identifying and exploring the computer programs and applications used in the learning process. A total of 18 applications and programs were put into use. These applications were measured using a 4-point scale outlining the amount of use (high, moderate, low, never).

Motivation toward e-Learning Scale

This scale was designed by the researcher to measure the level of motivation in students toward e-learning in the following areas and dimensions:

- Communicating through computer applications, measured by 8 items;

- $\quad$ Ability to use computer application in learning, measured by 8 items;

- The usefulness of information technology in enhancing learning, measured by 7 items;

- Aspirations and attitudes toward the technological future and e-learning, measured by 7 items.

This scale takes the following components of motivation into consideration:

Positive attitudes toward computers, related to the importance of computers in terms of ideas and beliefs, Inclina- tion, presented in the behaviors toward using computers in all fields of knowledge and communication, The emotional aspect which is represented by a learner's desire, enjoyment, and preferences in using applications and computer programs, are preferred over any other learning method. The Motivation toward e-learning scale is characterized by high reliability and validity values. Its content not only possesses high levels of validity, but is characterized by its modern and holistic items (with 30 items in total). The scale's validity was determined by a committee of expert and professional judges who are knowledgeable in pedagogy sciences, psychology, and e-learning technologies. Furthermore, each member of the committee was asked to provide feedback regarding the linguistic structure, accuracy, and clarity of the items, and in regards to its suitability for measuring students' perceptions and attitudes. Their input was taken into consideration and the items were altered accordingly. The committee's revision of the scale is proof of the validity of its content. Moreover, the researcher applied the scale on a pilot sample consisting of 48 students, resulting in a reliability coefficient of 0.891 using the Kuder-Richardson formula (KR-20).

\section{Limitations}

The limitations of the study findings are as follows:

- This study is limited to undergraduate students at the University of Petra, a private university in Amman, Jordan.

- The results are limited to the reliability and validity of the scales specifically designed for this study.

\section{RESULTS AND DISCUSSION}

\section{Results Related to the First Question}

The study aims to investigate the extent to which undergraduate students use computer applications and online programs and explored the correlation between the levels of using these applications and motivation toward e-learning, Furthermore, the study aimed to reveal the correlation between the levels of integrating computer programs and academic achievement (scores). Frequencies and percentage of use were calculated. The results indicate that social media applications where the most frequently used, followed by mobiles and e-mail. All these applications are considered informal and limited to social communication. To determine the existence of any statistically significant differences in program and application use among students from different faculties at the university, mean and standard deviation values were calculated. The data indicates that students in different majors and faculties varied in their use of a number of applications which include search engines, forums, MSN, Facebook, YouTube, Google Translator, Wikipedia, and E-mail providers. However, these differences are insignificant.

Findings indicate that the student use of computer applications was moderate, and that students use the applications included in the study to very similar extents, where social media networks and mobiles take the lead with insignificant differences. These applications are not often used in the 
learning process, but rather solely for communication purposes. Moreover, the findings indicate that students' use of these various forms of different applications included in this study were closely related in the levels (high, moderate, and low) which reflects the lack of an administrative educational system that would integrate and implement such technologies; but rather that e-learning is optional for students and professors. This leads us to conclude that e-learning is an elective form of learning, and has not been integrated successfully in any well-planned higher education system by decision makers and administrators. This result may be attributed to the services provided by the university and cannot be dispensed with the student such as registration for the semester and seeing the marks in courses, in addition to the communications and university publications and all these employed social networking applications such as e-mail and all available on the smartphone, the use of which is enhanced through availability and free of charge at the university. This result is consistent with what was mentioned in the study by Abdel Daim and Nassar (2012). This reflects the use of computer programs and applications in Arab universities and gives an indication of the need to plan the integration of these applications (networks, mobile and Internet) in the learning and teaching of university courses in a wide way, because students are more used to these programs and applications.

To determine the undergraduates' levels of motivation toward e-learning, percentages, totals, and mean values of students' scores on the Motivation toward e-learning scale were calculated. The researcher has chosen to categorize students as highly motivated (high) if their score fell between $75-100 \%$, moderately motivated (moderate) if they scored between $40-74 \%$, and poorly motivated (low) if their scores were below 40\%. Table 1 categorizes students accordingly.

When analyzing the data present in the above table, we find that students who had a low level of motivation to ward e-learning were $(54.8 \%)$ with mean $(22.98)$, whereas those with moderate levels were (31.4\%) with mean (58.15), meaning that $(86.2 \%)$ of the sample had low-to moderate motivation levels. This means that students do not have sufficient motivation toward e-learning. This shows the importance of the role of the university administration and its instructors in developing plans and programs which explain the effectiveness and the importance of employing computer programs and their applications effectively and attractively, as well as encourage students to employ these programs and applications in the educational process and clarify their importance as well as the role of these effective applications in education.

Findings related to the correlation between the level to which technological applications and computer programs were used and motivation toward e-learning and academic achievement (score) was calculated. Findings indicated a correlation between the extent to which applications and computer programs were used and students' scores on the motivation toward e-learning scale, with a Pearson correlation coefficient of $(0.310)$, which is a positive correlation. Although there is a positive correlation between the levels of use both computer programs and its applications and motivation towards e-learning, this correlation is acceptable but not high. The reason is that students' use of computer applications mostly has been limited to social networks, mobile, internet and YouTube, all of which are not actually used in the education process. Despite the simple use of applications, this has influenced motivation towards e-learning. These findings are consistent with previous studies which concluded that integration of computers and computer applications and programs onto the learning process creates a positive motivation toward e-learning. Such ideas are particularly consistent with Hartnett et al. (2011a, b); Anqithan (2010); Nehme (2010); Kim and Frick (2011); Abdel Daim and Nassar, (2012), Law, Lee and Yu (2010); Liaw, Huang and Chen (2007) and Selim (2007). The previously mentioned papers have all tackled motivation toward learning in the e-learning environment. Their findings give strong indications that we are capable of increasing motivated learners though setting up learning environment based on the integration of computer applications and programs, and thus achieving effective learning.

Also, the results show no such correlation existing between the extent to which applications and computer programs were used and students' academic achievement (score) with a correlation coefficient of (0.002). But the results of this study differ from what was reported in other studies that confirmed in existing correlation between the use of computer applications and academic achievement.

The motivation towards e-learning is the continuous effort of the student towards learning. It is necessary to investigate the internal and external factors affecting the motivation towards e-learning in order to develop the appropriate plans and programs in preparation for the stage of e-learning in the university study in Jordan, To increase student motivation towards e-learning and improve the effectiveness of e-learning, it is important to enhance education and training to give students a better understanding of computers and related technology through secondary education curricula.

\section{Results Related to the Second Question}

To determine whether there are statistically significant differences in the level of motivation toward e-learning and the level of using computer applications and programs on the variable of sex, faculty at which undergraduates are enrolled and the academic level variable, the researcher calculated mean and standard deviation values separately for males and females on the Motivation toward E-learning scale and the level of computer program and application use in the learning process scale. Furthermore, the t-values were calculated.

Mean values of male students' scores on the motivation toward e-learning scale were (44.55) while those of female students on the same scale reached (40.2). The t-values were calculated. This indicates a statistical significant difference at $(\alpha=0.05)$ in favor of male students. Mean values of male students' scores on the amount of computer applications and programs scale were (50.35) while those of female students on the same scale reached (48.22). The t-values indicate no significant difference. Although male students are no different from female students in the level of use of software and computer applications, they differ in their motivation 
towards e-learning. This result differs from the study of Abdel-Daim and Nassar (2012), which emphasized the impact of e-learning environments on learners' motivation This can be explained by the fact that male students consider the importance of employing computer programs and e-learning in the future profession because of the community culture which focuses on the importance of work and job and the workability of men more than the importance of working for women. In addition, this finding is in line with the findings of a study by Durndell and Hagg (2002) that confirmed that the level of anxiety in females is higher than that of men as a result of the use of computer programs and applications. The study of Ong and Lai (2006) also showed that male awareness of the benefit of computer applications and e-learning is better than that of females. The results of the study by Owate, Afolabi and Akanwa (2017) shows that female students' aged 15-25 are more interested in using the software and computer applications used in e-learning and are more self-confident than male students in dealing with software. However, males use computer programs such as games, music, the Internet, data processing and drawing programs at home that are more likely to be used by females. The reason is that male students use computer applications more than females and are more self-confident in dealing with technology due to their roles and the biased view of the role of male and female students in the use and employment of e-learning in educational systems in the Middle East.

In addition, the researcher has calculated the mean and standard deviation values on students' scores on the Motivation toward E-learning scale, and grouped these scores according to the different faculties students belong to.

The Scheffe post Hoc indicate that there is a statistically significant difference between the mean of Arts and Science students' scores and Engineering students scores in favor of Arts and Science students, as well as between the mean of Administrative Sciences students' scores and Engineering students' scores in favor of Administrative Science students. The results of this study are in line with what was stated in Abdul Daim and Nasar's study (2012), who stressed that the motivation of the students of the faculties of education, science and administration is better than the motivation of the students of scientific colleges such as engineering and pharmacy towards e-learning. This can be explained by the fact that learning through lectures and traditional teaching in these colleges makes students feel bored, unlike networking, software, and computer applications that are more fun and thus increase their motivation to learn through them, unlike students in scientific colleges such as pharmacy and engineering, which are dominated by learning through laboratories and projects, which are non-boring methods.

To determine if there exist any statistically significant differences in the level of motivation toward e-learning on the academic level variable, mean and standard deviation values of students' scores on the Motivation toward e-learning scale were calculated, The F-value was calculated concluding that a statistical significance exists. The results indicate that there is a statistically significant difference between the mean of Freshmen's scores and Sophomores scores in favor of Freshmen, as well as between the mean of Freshmen scores and Juniors scores in favor of Freshmen. This result is in line with the study by Abdul Daim and Nassar (2012) which concludes that freshmen motivation toward e-learning is greater than those of older students. This can be explained by the fact that new students are more receptive to technology because they understand its importance in learning because of what the University does at the beginning of the enrollment of students in the university to clarify the role and importance of the use of software and computer applications in education. As well as to inform them of future university plans that emphasize this role during the courses held during the first academic year of the university student, and this result is inconsistent with the study of Nehme (2010) which showed that motivation to e-learning of the older student is better than those at the initial level students. The difference is due to the difference in society and the nature of the learning environments used. Owate, Afolabi and Akanwa (2017) believe that the academic level or age are not affecting factors if we provide students with training programs and sufficient preparation to deal with the programs and applications related to e-learning and take this training official status in public education.

In regards to the relationship between academic achievement (score) and motivation toward e-learning, findings indicated that no statistically significant differences exist between the two aforementioned variables. Furthermore, calculations found no statistically significant differences between the extent to which students use computer applications and programs and their academic scores. This result can be explained by relying on the previous result that showed that the most used computer applications and programs used are the applications of social networks and e-mails given the nature of these applications, we find that students tend to use software and applications in social communication rather than in the educational application which shows that there is no correlation between academic achievement and motivation for e-learning.

However, the findings of the current study conflict with a number of previous studies which have indicated that e-learning has an impact on academic achievement and motivation. Arguably, the use of computer programs and applications, social media networks, and the internet fulfill students' needs and are filled with stimulants in multimedia formats, such as audio, visual representations, and animated objects. This makes e-learning more suitable and more prompting to students, thus boosting their motivation toward learning. We can say that the correlation between the level of use of software and computer applications as well as the motivation towards e-learning will be present and has positive value when the e-learning process in university education is a formal and compulsory option and compels the student to deal with computer applications as well as e-learning. Consequently, this will be reflected in the achievement of the university student.

\section{CONCLUSION}

Few studies have examined the level of use computer applications and the impact of this use on the motivation towards 
e-learning, especially in the Middle East, where the employment of computer and information technology is new in the educational process at the university level.

The motivation for learning in general and motivation for e-learning are important because e-learning environments are learner-centric and focus on student active roles, which is the focus of the constructivist theory in education. The focus of educators in e-learning has become great on the design of E-learning environments, and continuous research on the factors that influence learner motivation towards this type of learning has become necessary. The study examined the level of students' use of computer programs and applications and their effects on motivation towards e-learning. The study concluded that there is a positive correlation between them. According to the results of this study, applications of social networks and e-mail were the most used. It is necessary to focus on factors affecting e-learning environments and to find factors that increase the motivation of learners through these environments.

The current study is evidently significant in highlighting the importance of using computer programs and applications in boosting students' motivation toward e-learning. Tackling this issue can help professionals and educational e-learning program coordinators integrate information technology and social media networks in ways that potentially serve the educational process. Furthermore, it allows for the fulfillment of learners' goals, and serves the adaptability of the educational process to modern teaching. More studies need to look at the standards of good educational design for programs that are used in e-learning so as to increase the motivation of learning among Jordanian university students.

\section{REFERENCES}

Abdul Daim, K.M., \& Nassar A.M. (2012). The use of e-learning environments and its relation to the performance motivation of Al-Quds Open University students in the North Gaza Educational Zone, Palestinian Journal of Open Education, 3(6), 171-216.

Al-Isawi, T. (2011). The Concept of Motivation. Faculty of Primary Education, Babel, Iraq. Retrieved from http:// www.uobabylon.edu.iq/uobColeges/service_showarticle. $\operatorname{aspx}$ ?fid=11\&pubid=2716

Al-Jaberi, N. (2011). Students' and Teachers' Attitudes toward E-Learning. Childhood and Pedagogy Magazine. 6. University of Alexandria.

Alrashdan, Abdullah, Janini, Naeem, H., (2006), introduction to education and teaching, Dar El Shorouk for Publishing \& Distribution, (ed.5).

Anqithan, I. (2009). Learners' Attitudes toward using Technology in Higher Education, Professional Development Staff in the Higher Education Community Seminar, Riyadh.

Durndell, A., \& Hagg, Z. (2002). Computer self-efficacy, computer anxiety, attitudes towards the Internet and reported experience with the Internet, by gender, in an East European sample. Computers in Human Behavior, 18(5), 521-535.

Brophy, J. E. (2010). Motivating students to learn: Taylor \& Francis
Gabrielle, D. (2003). The effects of technology-mediated instructional strategies on motivation, performance, and self-directed learning. In EdMedia: World Conference on Educational Media and Technology (pp. 2568-2575). Association for the Advancement of Computing in Education (AACE).

Ghergulescu, I., \& Muntean, C. H. (2010a). MoGAME: Motivation based Game Level Adaptation Mechanism.

Ghergulescu, I., \& Muntean, C. H. (2010b). Supporting assessment of motivation in gaming based e-learning: IADIS International Conference on Cognition and Exploratory Learning in Digital Age (CELDA 2010).

Giesbers, B., Rienties, B., Tempelaar, D., \& Gijselaers, W. (2013). Investigating the relations between motivation, tool use, participation, and performance in an e-learning course using web-videoconferencing. Computers in $\mathrm{Hu}$ man Behavior, 29(1), 285-292.

Harandi, S. R. (2015). Effects of e-learning on Students' Motivation. Procedia-Social and Behavioral Sciences, 181, 423-430.

Hartnett, M., George, A. S., \& Dron, J. (2011a). Being together-factors that unintentionally undermine motivation. Journal of Open Flexible and Distance Learning, 15(1), 1-16.

Hartnett, M., George, A. S., \& Dron, J. (2011b). Examining motivation in online distance learning environments: Complex, multifaceted and situation-dependent. The International Review of Research in Open and Distributed Learning, 12(6), 20-38.

Keller, J. M. (2008). First principles of motivation to learn and e3-learning. Distance Education, 29(2), 175-185.

Kim, K. J., \& Frick, T. W. (2011). Changes in student motivation during online learning. Journal of Educational Computing Research, 44(1), 1-23.

Kim, S.S. and Malhotra, N.K. (2005). A longitudinal model of continued IS use: an integrative view of four mechanisms underlying post adoption phenomena, Management Science, 51(5), 741-55.

Law, K. M., Lee, V. C., \& Yu, Y. T. (2010). Learning motivation in e-learning facilitated computer programming courses. Computers \& Education, 55(1), 218-228.

Liaw, S. S., Huang, H. M., \& Chen, G. D. (2007). An activity-theoretical approach to investigate learners' factors toward e-learning systems. Computers in Human Behavior, 23(4), 1906-1920.

Mahdizadeh, H., Biemans, H., \& Mulder, M. (2008). Determining factors of the use of e-learning environments by university teachers. Computers \& Education, 51(1), 142-154.

Martens, R., Gulikers, J., \& Bastiaens, T. (2004). The impact of intrinsic motivation on e-learning in authentic computer tasks. Journal of computer assisted learning, 20(5), 368-376.

Miljković, B. D., Petojević, A. V., \& Žižović, M. R. (2016). Monitoring the effect of motivation on mastering knowledge and skills in distance learning systems. Vojnotehnički glasnik, 64(4), 1009-1032.

Miqdad, M. (2010). Motivation toward Learning in E-Learning Students. E-Learning Conference for the Advancement of Cognitive Communities, Bahrain.

Mullen, G. E., \& Tallent-Runnels, M. K. (2006). Student outcomes and perceptions of instructors 'demands and 
support in online and traditional classrooms. Internet \& Higher Education, 9(4), 257-266.

Nehme, M. (2010). ELearning and Students' Motivation. Legal Education Review, 20(1/2), 223.

Ong, C. S., \& Lai, J. Y. (2006). Gender differences in perceptions and relationships among dominants of e-learning acceptance. Computers in human behavior, 22(5), 816-829.

Owate, C. N., Afolabi, M., \& Akanwa, P. C. (2017). Demographic variables and students use of e-learning resources in public secondary school libraries in Rivers State of Nigeria. International Journal of Educational Administration and Policy Studies, 9(2), 10-27.

Rovai, A. P., Ponton, M. K., Wighting, M. J., \& Baker, J. D. (2007). A comparative analysis of student motivation in traditional classroom and e-learning courses. International Journal on E-Learning, 6(3), 413.

Ryan, R.M. \& Deci, E.L. (2000), Intrinsic and extrinsic motivations: classic definitions and new directions, Contemporary Educational Psychology, 25(1), 54-67.

Shenker, J. I., Goss, S. A., \& Bernstein, D. A. (1996). Instructor's Resource Manual for Psychology. Boston: Houghton-Mifflin.
Shroff, R. H., Vogel, D. R., Coombes, J., \& Lee, F. (2007). Student e-learning intrinsic motivation: A qualitative analysis. Communications of the Association for Information Systems, 19(1), 12.

Selim, H. M. (2007). Critical success factors for e-learning acceptance: Confirmatory factor models. Computers \& Education, 49(2), 396-413.

Sun, P. C., Tsai, R. J., Finger, G., Chen, Y. Y., \& Yeh, D. (2008). What drives a successful e-Learning? An empirical investigation of the critical factors influencing learner satisfaction. Computers \& education, 50(4), 1183-1202.

Topal, A. D. (2016). Examination of University Students' Level of Satisfaction and Readiness for E-Courses and the Relationship between Them. European Journal of Contemporary Education, 15(1), 7-23.

Wu, W., \& Hwang, L. Y. (2010). The effectiveness of e-learning for blended courses in colleges: A Multi-Level Empirical Study. International Journal of Electronic Business Management, 8(4), 312-322. 